\title{
Outcome of low-Lying placenta at 18-22 Weeks- A Prospective Observational Study
}

\author{
Kakali Sinha Karmakar¹, Lagnajita Paria², Debasish Chattopadhyaya ${ }^{3}$
}

\begin{abstract}
${ }^{1}$ Professor, Department of Obstetrics and Gynaecology, College of Medicine and Sagore Dutta Hospital, Kolkata, West Bengal, India. ${ }^{2} \mathrm{MS}$, Department of Obstetrics and Gynaecology, ESI Hospital, Maniktala, Kolkata, West Bengal, India. ${ }^{3}$ Associate Professor, Department of Obstetrics and Gynaecology, Murshidabad Medical College, Murshidabad,

Kolkata, West Bengal, India.
\end{abstract}

\section{ABSTRACT}

\section{BACKGROUND}

Haemorrhage contributes to $25 \%$ of maternal deaths worldwide. Placenta previa i.e. Placenta attached to lower uterine segment, is an important cause of antepartum and postpartum haemorrhage and is associated with some foetal and neonatal complications as well. Most of the low-lying placentas found at early weeks of pregnancy migrate to upper uterine segment before term or before delivery.

\section{METHODS}

This prospective observational study was conducted on the outcome of low-lying placenta at 18-24 weeks, in the Department of Gynaecology and Obstetrics, NRS Medical College, Kolkata from May 2013 to April 2014. 75 asymptomatic women with low lying placenta (distance less than or equal to $2 \mathrm{cms}$ from the internal cervical os), discovered by trans-abdominal USG and/or transvaginal sonography at 18 to 22 weeks of gestation. They were observed up to 6 weeks post-partum for maternal and foetal complications.

\section{RESULTS}

Placenta was found to migrate to upper uterine segment in $77.3 \%$ cases. Rate of migration decreased in placenta closer to os and overlapping the os. Migration was more in posterior placenta than anterior placenta which was statistically significant. Persistence of low-lying placenta at term was associated with higher age and increasing parity of the mother; in both these situations the association was statistically significant. H/o previous Caesarean section was associated with persistence of low-lying placenta about 1.9 times more commonly than in cases with no such history. Prior termination of pregnancy ( MTP) was associated with higher chance of persistence of low lying placenta at term or delivery ( $27.7 \%$ ) with odds ratio of 1.44; whereas multiple pregnancy (odd's ratio=1.1) and prior placenta previa (odd ratio 1.1) are minor risk factors for persistence of low lying placenta at term or delivery. Low lying placenta if associated with bleeding in early months showed less chance of migration at term or delivery. Higher incidence of mapresentation, atonic PPH, preterm birth and iatrogenic CS was found in persistent placenta previa group. Unlike other complications, there is slightly increased preterm delivery rate in migrated group also. Among foetal complications, IUGR and congenital anomalies, birth asphyxia, neonatal death were more common in persistent placenta previa group compared to migrated group, which was statistically significant.

\section{CONCLUSIONS}

So, cases found with low lying placenta in early months, should be assessed carefully regarding presence of risk factors of persistence in lower segment. Mother should be counselled regarding this possibility of migration and also maternal and foetal risks in case placenta persists in low position.

\section{KEY WORDS}

Antepartum Haemorrhage, Low-Lying Placenta, Placenta Previa, Placental Migration, Atonic PPH, Mal Presentation, Neonatal Outcome
Corresponding Author: Dr. Kakali Sinha Karmakar \#77B Baderaipur Road, Jadavpur, Kolkata-700032, West Bengal, India.

E-mail: drkskarmakar@rediffmail.com

DOI: $10.14260 /$ jemds/2019/654

Financial or Other Competing Interests: None.

How to Cite This Article:

Karmakar KS, Paria L, Chattopadhyaya D. Outcome of low-lying placenta at 18-22 weeks-a prospective observational study. J. Evolution Med. Dent. Sci. 2019;8(40): 3010-3013, DOI:
Submission 25-05-2019,

Peer Review 17-09-2019,

Acceptance 25-09-2019,

Published 07-10-2019. 


\section{BACKGROUND}

Haemorrhage is the most terrifying complication of pregnancy contributing to $25 \%$ of maternal deaths worldwide. Placenta previa is one important cause of antepartum haemorrhage and can also lead to postpartum haemorrhage. It is a condition characterised by insertion of placenta wholly or partially in the lower uterine segment. Painless, recurrent bleeding per vagina has been the hallmark of placenta previa and symptoms and signs are usually proportionate to the amount of blood loss. It complicates 0.4 - $0.8 \%$ of pregnancies but incidence changes with presence or absence of risk factors. ${ }^{1}$ Perinatal mortality rates are 3-4 times higher in placenta previa. ${ }^{2}$

Low lying placenta can be diagnosed with excellent accuracy from early antenatal period along with its grading. Transvaginal sonography is superior to transabdominal sonography in this indication. ${ }^{3}$ The incidence of low-lying placenta sonographically diagnosed in the $2^{\text {nd }}$ trimester ranges from $6-46 \%$ which decreases to as low as $0.5 \%$ at delivery. 4

Lower incidence at term is due to placental migration which is the positional change of the placenta from the lower segment to upper segment with advancing gestation and is due to net result of differential growth of two parts of placenta i.e., appropriate growth of the part attached to well vascularised fundus and degeneration of peripheral villi in the lower uterine segment that receives less blood supply. It is also due to differential growth rate of lower segment of uterus and placenta. This phenomenon is more pronounced in anterior than in posterior low-lying placenta. ${ }^{5}$

Most of the studies on low lying placenta are retrospective studies, case reports and concentrated on placental migration. The aim of this study is to evaluate pregnancy outcome of cases where a low-lying placenta defined as margin of placenta at a distance of $<2 \mathrm{~cm}$ from internal os as detected at 18-22 weeks of pregnancy.

\section{METHODS}

This prospective observational study was conducted in the Dept. of Gynaecology and Obstetrics, NRS Medical College, Kolkata from May 2012 to April 2013, after the protocol had received clearance from Institutional Ethics Committee, NRS Medical College.

Among all the women attending antenatal clinic, consecutive 75 women were with low lying placenta (distance less than equal to $2 \mathrm{~cm}$ from the internal cervical os) discovered by trans-abdominal USG and/or transvaginal solography at 18 to 22 weeks of gestation but having no symptoms of bleeding, were taken for study, after they met the inclusion criteria and had given informed consent. These cases were followed by TAS or TVS at 30-32 weeks and then at 2-3-week interval to note the placental migration till term/delivery whichever was earlier. Clinical presentation, risk factors, gestational age at delivery, mode of delivery, Intrapartum and postpartum complications, time of delivery, birth weight, 5-minute Apgar score were recorded. Mother and baby were followed up till 6 weeks post-partum.

\section{RESULTS}

\begin{tabular}{|c|c|c|c|c|c|}
\hline $\begin{array}{c}\text { Location of } \\
\text { low-Lying } \\
\text { placenta at } \\
18-22 \\
\text { Weeks } \\
\end{array}$ & $\begin{array}{c}\text { No of low-Lying } \\
\text { placenta at 18-22 } \\
\text { Weeks (\%) N=75 }\end{array}$ & $\begin{array}{c}\text { No of low-Lying } \\
\text { placenta at } \\
\text { Term/ Delivery } \\
\text { (\%) N=17 }\end{array}$ & $\begin{array}{c}\text { Migrated } \\
\text { placenta at } \\
\text { Term (\%) } \\
\mathrm{N}=\mathbf{5 8}\end{array}$ & $\begin{array}{l}\text { Likely } \\
\text { hood } \\
\text { Ratio }\end{array}$ & $95 \%$ CI \\
\hline Within $1-2 \mathrm{~cm}$ & $38(50.6 \%)$ & $1(3 \%)$ & $37(97 \%)$ & 0.0922 & $\begin{array}{l}0.0136 \\
\text { to } \\
0.624\end{array}$ \\
\hline $\begin{array}{c}\text { Not overlap- } \\
\text { ing but within } \\
1 \mathrm{~cm} \\
\end{array}$ & $21(28 \%)$ & $2(10 \%)$ & $19(90 \%)$ & 0.359 & $\begin{array}{c}0.0928 \\
\text { to } \\
1.390 \\
\end{array}$ \\
\hline $\begin{array}{l}\text { Overlapping } \\
<2.5 \mathrm{~cm}\end{array}$ & $12(16.2 \%)$ & $10(84 \%)$ & $2(16 \%)$ & 17.059 & $\begin{array}{c}4.129 \\
\text { to } \\
70.484 \\
\end{array}$ \\
\hline $\begin{array}{l}\text { Overlapping } \\
>2.5 \mathrm{~cm}\end{array}$ & $4(5.3 \%)$ & $4(100 \%)$ & $0(0 \%)$ & $\infty$ & $\begin{array}{l}1.517 \\
\text { to } \\
\infty\end{array}$ \\
\hline
\end{tabular}

Table 1. Placental Migration in Relation to Distance from Internal-Os

Table 1 shows decreased rate of migration as the placenta becomes closer to internal os or overlaps it. Placenta that overlapping $>2.5 \mathrm{~cm}$ at $18-22$ weeks has $0 \%$ migration at term/delivery.

\begin{tabular}{|c|c|c|c|}
\hline $\begin{array}{c}\text { Position of } \\
\text { placenta }\end{array}$ & $\begin{array}{c}\text { No. of low-Lying } \\
\text { placenta at 18-22 } \\
\text { Weeks (\%) }\end{array}$ & $\begin{array}{c}\text { No. of low-Lying } \\
\text { placenta at Term/ } \\
\text { Delivery (\%) }\end{array}$ & $\begin{array}{c}\text { Migrated } \\
\text { placenta at } \\
\text { Term (\%) }\end{array}$ \\
\hline Posterior & 21 & $1(4.7 \%)$ & $20(95.3 \%)$ \\
\hline Anterior & 54 & $16(29.6 \%)$ & $38(70.4 \%)$ \\
\hline Table 2. Placental Migration in Relation to the \\
placenta. (n=75)
\end{tabular}

As shown in table 2, anteriorly situated low lying placenta showed lesser migration $(70.4 \%)$ than posteriorly situated placenta $(95.3 \%)$. And it is statistically significant $(\mathrm{p}$ value $=$ 0.04 , odd ratio $=8.42$ )

\begin{tabular}{|c|c|c|c|c|}
\hline Age & $\begin{array}{c}\text { No of low-Lying } \\
\text { placenta } \\
\text { At 18-22 } \\
\text { Weeks }\end{array}$ & $\begin{array}{c}\text { No of low-Lying } \\
\text { placenta at Term/ } \\
\text { Delivery (\%) }\end{array}$ & $\begin{array}{c}\text { Likelihood } \\
\text { Ratio }\end{array}$ & $\begin{array}{c}\mathbf{9 5 \%} \\
\text { Confidence } \\
\text { Limit }\end{array}$ \\
\hline$<20$ yr. & 20 & $2(10 \%)$ & 0.500 & 0.130 to 1.917 \\
\hline 20 to $<25$ yrs. & 26 & $3(11.5 \%)$ & 0.577 & 0.200 to 1.663 \\
\hline 25 to $<30$ yrs. & 16 & $2(12.5 \%)$ & 0.625 & 0.160 to 2.439 \\
\hline 30 to $<35$ yrs. & 9 & $5(55.5 \%)$ & 2.778 & 1.083 to 7.127 \\
\hline$>/=35$ & 4 & $3(75.3 \%)$ & 3.750 & 0.934 to 15.064 \\
\hline \multicolumn{3}{|c|}{ Table 3. Frequency Distribution of Study Population According to } \\
Age Group and Site of placenta (n=75) \\
\hline \multicolumn{5}{|c|}{} \\
\hline
\end{tabular}

Statistical Test

$\mathrm{X}^{2=} 17.65 \mathrm{p}=0.0014 . \mathrm{df}=4$

So, the result is statistically significant.

Persistence of low lying placenta at term or delivery is increased with maternal age (Table 3) as in this study persistence of low lying placenta at term or delivery consisted of $10 \%$ in $<20$ year, $11.5 \%$ in 20 to $<25$ year, $12.5 \%$ in $25-<30$ year, $55.5 \%$ in 30 to $<35$ year and $75.3 \%$ in $>/=35$ age group and this difference is statistically significant with $p$ value being 0.0014 .

\begin{tabular}{|c|c|c|c|c|c|}
\hline Parity & $\begin{array}{c}\text { Low-Lying } \\
\text { placenta at } \\
\mathbf{1 8 - 2 2} \text { Weeks } \\
\text { (\%) n=75 }\end{array}$ & $\begin{array}{c}\text { No of low-Lying } \\
\text { placenta at Term/ } \\
\text { Delivery (\%) } \\
\mathbf{n = 1 7}\end{array}$ & $\begin{array}{c}\text { Migrated } \\
\text { placenta at } \\
\text { Term (\%) } \\
\mathbf{n = 5 8}\end{array}$ & $\begin{array}{c}\text { Likely- } \\
\text { hood } \\
\text { Ratio }\end{array}$ & 95\% CI \\
\hline P o & $5(6.66 \%)$ & $0(0 \%)$ & $5(100 \%)$ & 0.000 & 0.000 to 5.936 \\
\hline P 1 & $28(37.3 \%)$ & $5(17.8 \%)$ & $23(82.2 \%)$ & 0.742 & 0.333 to 1.654 \\
\hline P 2 & $38(50.6 \%)$ & $9(23.6 \%)$ & $29(76.4 \%)$ & 1.059 & 0.631 to 1.775 \\
\hline $\begin{array}{c}\text { P 3 and } \\
\text { above }\end{array}$ & $4(5.3 \%)$ & $3(75 \%)$ & $1(25 \%)$ & 10.235 & 1.137 to 92.162 \\
\hline
\end{tabular}

Table 4. Distribution of Study Population According to

Previous 
Statistical Test

$X^{2=7.34 . ~} d f=2 . p=0.026$.

Table 4 shows increased parity associated with persistence of low-lying placenta at term or delivery and it is statistically significant as $p$ value is 0.026 .

\begin{tabular}{|c|c|c|c|c|c|}
\hline $\begin{array}{l}\text { Predisposing } \\
\text { Factors }\end{array}$ & & \begin{tabular}{|c|} 
No of low- \\
Lying \\
placenta \\
at $18-22$ \\
Weeks
\end{tabular} & $\begin{array}{c}\text { No of low-Lying } \\
\text { placenta at } \\
\text { Term/ } \\
\text { Delivery (\%) }\end{array}$ & $\begin{array}{c}\text { Migrated } \\
\text { placenta } \\
\text { at Term } \\
(\%)\end{array}$ & $\begin{array}{l}\text { Odds } \\
\text { Ratio }\end{array}$ \\
\hline \multirow{2}{*}{ Prior LSCS } & Present & 12 & $4(33.3 \%)$ & $8(66.6 \%)$ & \multirow{2}{*}{1.9} \\
\hline & Absent & 63 & $13(20.6 \%)$ & $50(79.4 \%)$ & \\
\hline \multirow{2}{*}{ Multiple pregnancy } & Present & 4 & $1(25 \%)$ & $3(75 \%)$ & \multirow{2}{*}{1.1} \\
\hline & Absent & 71 & $16(21.3 \%)$ & $55(78.7 \%)$ & \\
\hline \multirow{2}{*}{$\begin{array}{c}\text { Prior termination of } \\
\text { pregnancy }\end{array}$} & Present & 18 & $5(22.5 \%)$ & $13(77.5 \%)$ & \multirow{2}{*}{1.44} \\
\hline & Absent & 57 & $12(21 \%)$ & $45(79 \%)$ & \\
\hline \multirow{2}{*}{$\begin{array}{c}\text { Placenta previa in } \\
\text { previous pregnancy }\end{array}$} & Present & 4 & $1(25 \%)$ & $3(75 \%)$ & \multirow[b]{2}{*}{1.1} \\
\hline & Absent & 71 & $16(22.5 \%)$ & $55(77.5 \%)$ & \\
\hline $\begin{array}{r}\text { Table 5. Dis } \\
\mathrm{Pr}\end{array}$ & . & 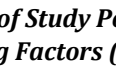 & Ia & ing tc & \\
\hline
\end{tabular}

More than one $(>1)$ predisposing factor are present in some cases. Table 5 shows that, h/o previous caesarean section was associated with persistence of low lying placenta at term or delivery $(33.3 \%$ ) (odd ratio $=1.9$ ) So it was shown that those who had h/o prior LSCS had 1.9 times chances of persistence of placenta previa at term or delivery than those who didn't have h/o prior LSCS. Prior termination of pregnancy (MTP) was associated with higher chance of persistence of low-lying placenta at term or delivery $(27.7 \%)$ with odd ratio 1.44. Multiple pregnancy (odd's ratio=1.1) and prior placenta previa (odd ratio 1.1) are minor risk factors of persistence of low-lying placenta at term or delivery.

\section{DISCUSSION}

In the present study, out of 75 low-lying placentae, detected at 18-22 weeks 58 (77.3\%) migrated. Mustafa et al,6 in 2002 found in a longitudinal study an incidence of low-lying placenta of $3.9 \%$ between $20-24$ weeks, $1.9 \%$ at term. Lauria et al in 1996 found an incidence of low-lying placenta at 1520 weeks of $1.1 \%$, with $14 \%$ of these still present at delivery.

This table 1 shows decreased rate of migration as the placenta become closer to internal os or overlaps it. Placenta that overlapping $>2.5 \mathrm{~cm}$ at $18-22$ weeks has $0 \%$ migration at term/delivery. Shravage Jyotsna $\mathrm{C}$ et al, 7 the rate of placental migration was highest that is $91.66 \%(22 / 24)$ where the initial distance between the lower edge of the placenta and the internal os was more than $2 \mathrm{~cm}$.

As shown in table 2, anteriorly situated low lying placenta showed lesser migration (70.4\%) than posteriorly situated placenta (95.3\%) which is statistically significant. Ruparelia et $a,^{5}$ Shravage Jyotsna et $\mathrm{al}^{8}$ found in their study of placenta previa anteriorly situated low lying placenta showed lesser migration (64.51\%) (20/31) when compared to posteriorly situated placenta (90\%) (9/10).

Persistence of low-lying placenta at term or delivery is increased with maternal age (Table 3) in this study. ClearyGold-man and associates ${ }^{8}$ showed those older than 35 years had a $1.1 \%$ risk for previa compared with that of $0.5 \%$ for women less than $<35$ years (2005). Ananth CV et $\mathrm{al}^{2}$ also found that increasing age is a risk factor for placenta previa.
This is probably due to overall decreased vascularity of uterus with age and thus the mechanism responsible for migration is not effective.

Table 4 shows increased parity associated with persistence of low-lying placenta at term or delivery and it is statistically significant as $\mathrm{p}$ value is 0.026 . Ananth CV et $\mathrm{al}^{2}$ reported that the likelihood of placenta previa increases in a dose response fashion with a greater parity. Babinszki et $\mathrm{al}^{9}$ reported that the $2.2 \%$ incidence of placenta previa at term in women para 5 or greater was increased significantly compared with that of low parity.

Table 5 shows that, h/o previous caesarean section was associated with persistence of low-lying placenta at term or delivery $(33.3 \%)$ with odds ratio= 1.9 . It has been suggested that damage to the endometrium during caesarean section predisposes to low implantation of the placenta and also impairs the ability of placenta to migrate. Prior termination of pregnancy (MTP) was associated with higher chance of persistence of low-lying placenta at term or delivery $(27.7 \%)$ with odd ratio 1.44. Multiple pregnancy (odd's ratio $=1.1$ ) and prior placenta previa (odd ratio 1.1) are minor risk factors of persistence of low-lying placenta at term or delivery. Sohrabi Davood, Parivar Kazem and Ebrahimi Sepideh in $2008^{10}$ concluded that potential risk factors for placenta previa included previous spontaneous or induced abortions, previous caesarean sections. To WW, Leung WC in $1995^{11}$ found that incidence of placenta previa was significantly increased in those with a previous caesarean section $(1.31 \%)$ compared with those with an unscarred uterus $(0.75 \%)$ (RR 1.64). This risk increased as the number of previous caesarean sections increased (R.R. 1.53 for one previous section, 2.63 for two or more). The incidence of an anterior placenta previa and placenta accreta was significantly increased in those with previous caesarean scars. Darios Getahun, Yinka Oyelese, Hamisu M Salihu in 200612 concluded that pregnancy after caesarean delivery was associated with increased risk of placenta previa $(0.63 \%)$ compared to those with vaginal delivery $(0.38 \%)$. (RR 1.5 , 95\% confidence interval [CI- 1.3-1.8]. Ananth and associates $(2003 \mathrm{~A})^{13}$ reported the rate of placenta previa $40 \%$ higher in multifoetal gestation. Multifoetal pregnancy has large placenta and the mechanism responsible for migration of placenta do not work effectively due to large placenta. In present study due to small number of patients, relationship with multifoetal gestation with persistence of low-lying placenta could not be assessed properly. Taylor VM (1993) ${ }^{14}$ concluded that women who report one or more induced or spontaneous abortions are 30\% more likely to have a subsequent pregnancy complicated by placenta previa than women without such a history.

\section{CONCLUSIONS}

Though low-lying placenta is a common finding in routine early trimester USG scan causing apprehension among patients and relatives, in most of the cases placenta migrates upwards at term or before delivery. Persistence of low-lying placenta is associated with higher maternal age, parity, anterior position, prior $\mathrm{h} / \mathrm{o}$ LSCS, $\mathrm{h} / \mathrm{o}$ bleeding in $2^{\text {nd }}$ and $3^{\text {rd }}$ 
trimester, shorter distance from margin and internal os. This will help to predict as to in which case placenta is likely to migrate. Cases with persistent low-lying placenta were associated with significantly high foetomaternal complications like atonic $\mathrm{PPH}$, prematurity, SGA baby, congenital anomaly, perinatal mortality. But cases with migrated placenta were not associated with more complications except the increased risk of preterm delivery. With better awareness about low-lying placenta among the general population, there is always need for proper counseling regarding probability of migration of placenta and risk factors for persistence in low position. Larger prospective trials are needed for better understanding of outcome in such cases.

\section{REFERENCES}

[1] Conje C, Taylor DJ. Bleeding in late pregnancy. In: James DK, Steer PJ, Weiner CP, et al. eds. High risk pregnancy: management options. $3^{\text {rd }}$ edn. Philadelphia: Saunders 2007;59:111, 1259.

[2] Ananth CV, Smulian JC, Vintzileos AM. The effect of placenta previa on neonatal mortality: a populationbased study in the United States, 1989 through 1997. Am J Obstet Gynecol 2003;188(5):1299-304.

[3] Lauria MR, Smith RS, Treadwell MC, et al. The use of second-trimester transvaginal sonography to predict placenta previa. Ultrasound Obstet Gynecol 1996;8(5):337-40.

[4] McClure N, Dornan JC. Early identification of placenta previa. Br J Obstet Gynecol 1990;97:959-61.

[5] Ruparelia BA, Chapman MG. Early identification of placenta previa (letter). $\mathrm{Br} \mathrm{J}$ Obstet Gynaecol 1991;98(5):499.
[6] Mustafa SA, Brizot ML, Carvalho MH, et al. Transvaginal ultrasonography in predicting placenta previa at delivery: a longitudinal study. Ultrasound Obstet Gynecol 2002;20(4):356-9.

[7] Jyotsna SC, Hema DA, Bellad MB. Assessment of placental migration in mid trimester low lying placenta. J Obstet Gynecol India 2009;59(4):317-9.

[8] Cleary-Goldman J, Malone FD, Vidaver J, et al. Impact of maternal age in obstetric outcome. Obstet Gynaecol 2005;105(5 Pt 1):983-90.

[9] Babinszki A, Kerenyi T, Torok 0, et al. Perinatal outcome in grand and great grand multiparity: effects of parity on obstetric risk factors. Am J Obstet Gynecol 1999;181(3):669-74.

[10] Davood S, Kazem P, Sepideh E. Selected pregnancy variables in women with placenta previa. Res J Obstet Gynecol 2008;1(1):1-5.

[11] To WW, Leung WC. Placenta previa and previous caesarean section. Int J Gynaecol Obstet 1995;51(1):2531.

[12] Getahun D, Oyelese Y, Salihu HM, et al. Previous caesarean delivery and risks of placenta previa and placental abruption. Am J Obstet Gynaecol 2006;107(4):771-8.

[13] Ananth CV, Demissie K, Smulian JC, et al. Placenta previa in singleton and twin births in the United States, 1989 through 1998: a comparison of risk factor profiles and associated conditions. Am J Obstet Gynecol 2003;188(1):275-81.

[14] Taylor VM, Kramer MD, Vaughan TL, et al. Placenta previa in relation to induced and spontaneous abortion: a population based study. Obstet Gynecol 1993;82(1):8891. 